\title{
0 Cinema Brasileiro, Hollywood e a Política da Boa Vizinhança da Década de 1930*: Um Panorama Para Carmen Miranda
}

\author{
Brazilian cinema, Hollywood and the Good Neighbourhood \\ Policy in the 1930s: a background for Carmen Miranda
}

por Káritha Bernardo de Macedo

\section{RESUMO}

Este artigo se presta a analisar o contexto cinematográfico da década de 1930 que alavancou Carmen Miranda como um símbolo nacional, envolvendo a profissionalização do cinema brasileiro, a penetração do cinema hollywoodiano, a influência da Política da Boa Vizinhança, e a relação destes fatores com a definição de uma identidade nacional. 0 estudo foi realizado a partir de análise de filmes hollywoodianos estrelados por Carmen Miranda e por revisão bibliográfica adequada. Na década de 1930 tem início as tentativas de industrialização do cinema brasileiro com os novos estúdios que se estabelecem no Rio de Janeiro. Nessa empreitada, o cinema brasileiro acaba descobrindo sua própria abordagem e transforma o carnaval em sua principal tópica, abrindo o caminho nas telas para a célebre cantora Carmen Miranda. Em pouco tempo Carmen foi cooptada pela Política da Boa Vizinhança estadunidense, como uma tática para penetrar a América Latina, abarcar aliados frente a Segunda Guerra Mundial e novos mercados para este país.

Palavras-chave Cinema Brasileiro; Nacionalismo; Hollywood; Carmen Miranda

\section{ABSTRACT}

This article proposes to analyze the cinematography context of the 1930 which leveraged Carmen Miranda as a national symbol, involving the professionalization of Brazilian cinema, the penetration of Hollywood cinema, the influence of the Good Neighbor Policy, and the relation of these factors with the definition of a national identity. The study was conducted on the analysis of Hollywood films starring Carmen Miranda and appropriate literature review. Began in the 1930 s the attempts of Brazilian cinema industrialization, with the new studios that are established in Rio de Janeiro. In this endeavor, the Brazilian film industry ends up finding out its own approach and puts Brazilian carnival as its major theme, leading the way on the screens to the famous singer Carmen Miranda. Soon Carmen was coopted by the U.S. Good Neighbor Policy, as a tactic to penetrate Latin America, allied front cover World War II and new markets for this country.

Keywords Brazilian Cinema; Nationalism; Hollywood; Carmen Miranda 


\section{A profissionalização do cinema brasileiro}

a revolução de 1930 dá início a intervenção do Estado no cinema nacional, e traz com ela maiores possibilidades de profissionalização do setor. No Rio de Janeiro as tentativas de industrialização cinematográfica chegavam com o estabelecimento de Cinédia (1930), da Brasil Vita Filme (1934) e da Sonofilmes (1937) (LIN0, 2007, p.170). Mas além das dificuldades técnicas que existiam num ramo que estava começando a se profissionalizar, este pessoal ainda tinha que enfrentar as exigências da mídia especializada, geralmente sugerindo que o cinema brasileiro deveria seguir os moldes estabelecidos nos Estados Unidos. A produções cinematográficas estadunidenses eram voltadas para uma indústria de fato, o objetivo era lucrar e sua estética comercial reconhecia que para fazer dinheiro, é preciso investir dinheiro, portanto, sabiam que um filme poderia ser mais apreciado pelo público se gastos notáveis com sua produção fossem divulgados (MALTBY, 2003, p. 113). Junto a isso, existia uma fábrica de estrelas, o principal sustentáculo, apoiados pelos princípios da boa aparência, luxo, higiene e juventude. Nessa linha, porém, recheada do discurso nacionalista, o crítico Paulo Wanderley, numa edição da revista Cinearte (1929), recomendava que o bom cinema brasileiro deveria selecionar suas imagens escolhendo apenas aquilo que merece ser projetado na tela, como o "progresso, as obras de engenharia moderna, nossos brancos bonitos, nossa natureza", e continuava afirmando que era contra os documentários porque muitos elementos indesejáveis poderiam aparecer (VIERA, 1987, p.131- 133). Portanto, para aquele entendimento, um cinema brasileiro de qualidade significaria a adoção irrestrita dos parâmetros de Hollywood.

Nesse panorama, Ademar Conzaga cria a Cinédia em 1930 dentro do modelo estadunidenses, ele "acreditava nas possibilidades comerciais de um cinema que associasse a estética hollywoodiana a conteúdos nacionais" (LINO, 2007, p.170). A produtora estreou com equipamentos de qualidade e pioneiros no Brasil, palcos simultâneos e funcionários permanentes. Adhemar Conzaga rapidamente agregou à produtora novas tecnologias e talentos que despontavam no ramo alterando completamente nosso cenário cinematográfico. 0 estúdio tinha um novo olhar para o cinema, foi precursor no gênero erotismo e trouxe referências europeias como o expressionismo alemão, a avant-garde francesa e o cinema de montagem soviético. As produções iniciais da Cinédia tinham um traço denso e simbólico, mas nem sempre o público brasileiro se mostrava apto a compreendê-las, tendo como grande marco o filme mudo de 1931, "Limite", que fez sucesso na Europa e no Brasil não. Com a falta do retorno esperado, surgem problemas financeiros que levam este, e outros estúdios a diversificar sua produção, sendo o pivô da sobrevivência os documentários educativos produzidos para o governo'. Humberto Mauro que

1 Sobre o projeto de cinema educativo e as produções de filmes históricos na primeira metade do século ver MORETTIN, Eduardo. A representação da história no cinema brasileiro (1907-1949). In Anais do Museu Paulista: História e Cultura Material, jan./dez. 1997, Nova Série, vol. 05, pp. 249-271. 
era um dos melhores diretores do período, tinha inúmeros documentários e filmes educativos em seu currículo (COMES, 1996, p.72; VIEIRA, 1987).

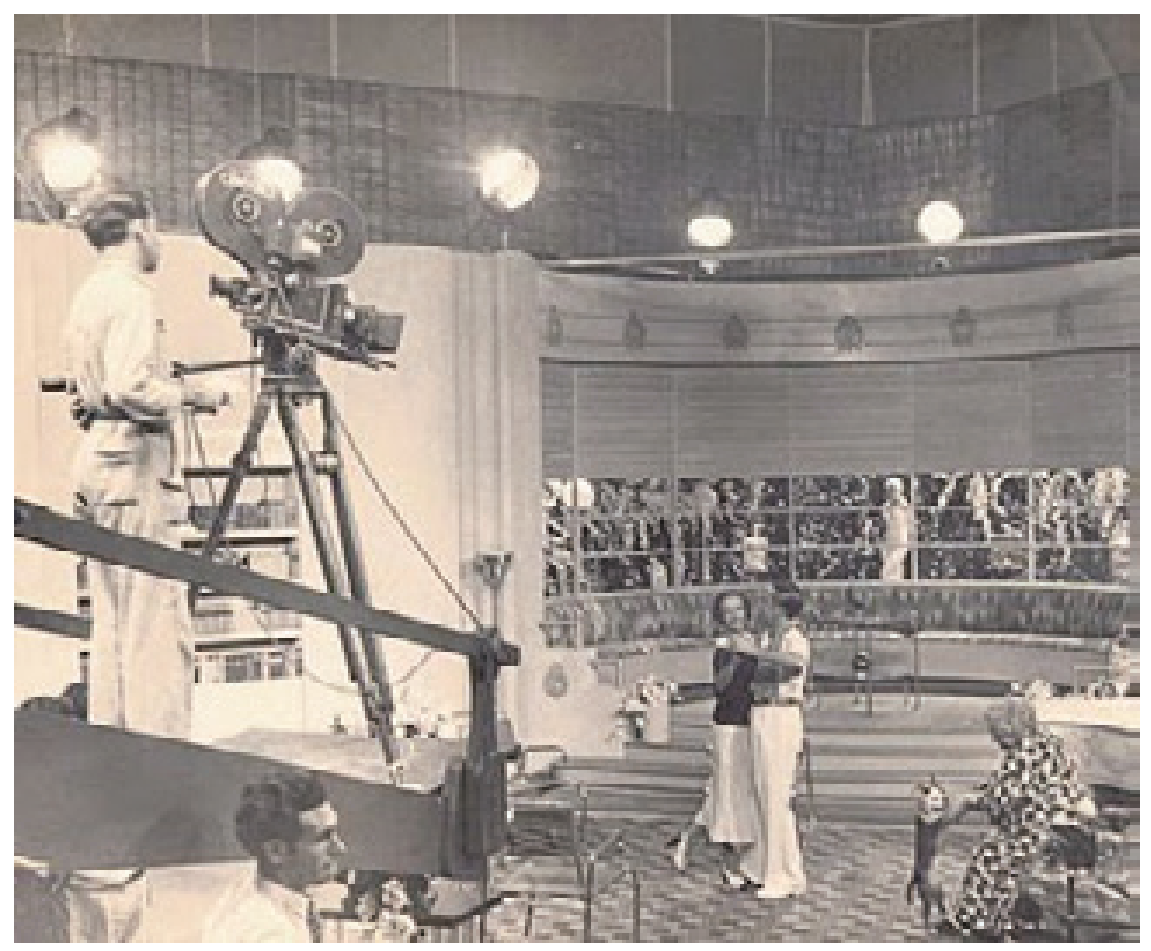

Figura 1 - Imagem de uma gravação nos estúdios da Cinédia

\section{0 carnaval ganha as telas}

os cineastas nacionais acreditavam que era pelos empecilhos técnicos que não conseguiam competir com o cinema dos Estados- Unidos2, desconsideravam a força econômica e cultural deste país e foi somente com o destaque à "brasilidade" que o cinema brasileiro se firmou. Perante a dificuldade em competir com o cinema estrangeiro falado, foi justamente na versão brasileira da cópia que as produções nacionais ganharam traços de identidade própria. Enquanto Hollywood retratava nas telas os musicais da Broadway sem dar muita atenção ao enredo, no

2 Como parte da Política de Boa Vizinhança, D.W Rowland, comenta que "A educação visual fazia parte do projeto civilizatório com o qual os Estados Unidos se empenhavam em alavancar a América Latina do seu patamar de desenvolvimento. Um dos investimentos nesse sentido foi a organização de uma frota de 200 caminhões que percorriam as cidades do interior dos países da América Latina, para atingir pessoas que normalmente não iam ao cinema e, sendo assim, não eram atingidos pela propaganda do CIAA. No caso do Brasil, como aponta a documentação do CIAA, não foram enviados caminhões, somente 61 projetores de filmes de $16 \mathrm{~mm}$, indicando uma possível parceria entre o CIAA e o Governo Brasileiro" (apud MAUD, 2005, p.58), que subsidiariam a amostra do cinema estadunidense. 


\section{Cinema Brasileiro, Hollywood e a Política da Boa Vizinhança da Década de 1930: Um Panorama Para Carmen Miranda}

Brasil os tupiniquins acompanharam a tendência e aproveitavam o que tínhamos, o teatro de revista, o rádio e o carnaval, centrados principalmente no Rio de Janeiro na década de 1940, sua localização motivou que as produções desse período fossem, sobretudo, cariocas (LIN0, 2007, p.170; GOMES, 1996, p.71). Com os filmes sonoros, agora era possível ver e ouvir as vozes famosas dos cantores e cantoras populares no rádio e nos discos, embalando sambas e marchinhas que faziam ainda mais sentido com o carnaval como cenário. A união entre cinema e música marcou os estúdios e o cinema feito no Rio pelas décadas de 1930, 1940 e 1950. Assim, foi somente à base de comédias carnavalescas que a indústria cinematográfica ganhava forma no Brasil (VIEIRA, 1987, p. 135-141).

0 lançamento de "Coisas Nossas" (1931), produzido na linha dos musicais de Hollywood pela Byington \& Cia., dona do selo Columbia no Brasil, e dirigido pelo estadunidense Wallace Downey, dá início a série carnavalesca e povoa a tela com as "estrelas brasileiras" da época, os cantores e cantoras do rádio. 0 sucesso desse filme abriu o caminho para "A Voz do Carnaval" (1933), uma mistura de documentário e ficção, com cenas de estúdio ainda rudimentares (BERNARDET, 2004, p.59). Muitas cenas do carnaval carioca foram filmadas e dizia-se que era a primeira vez que o carioca podia se ouvir. Nessa película Carmen Miranda aparece cantando, sua terceira aparição no cinema. 0 primeiro papel de Carmen Miranda no cinema foi como figurante no filme "A Esposa do Solteiro", ainda bem jovem, depois disso apareceu em "0 Carnaval Cantado", de 1932 (CASTRO, 2005, p.88; GARCIA, 2004, p.68).

Como parte do programa nacionalista, a fim de incentivar a produção nacional, em 1932, Vargas promulga um decreto que estabelece a obrigatoriedade de cada cinema exibir um filme nacional, mas ele entraria em vigor somente em 1934 (Decreto-lei 21.240/ 1932, apud LIN0, 2007, p.172). Ainda assim, o cinema nacional se debatia para sobreviver, em vista disso, alguns estúdios começaram a trabalhar em parcerias. Em 1935 a Cinédia se associa a Wallace Downey, da Waldow Filmes, e juntos produzem "Alô, Alô Brasil" (GOMES, 1996, p.72-73). Contando com várias celebridades do rádio, foi um grande sucesso lançado às vésperas do Carnaval que consolidou a parceria entre rádio e cinema. Nesse filme a exaltação ao nacional através da imagem do Rio de Janeiro fica evidente nas canções Primavera no Rio e Cidade Maravilhosa, interpretadas por Carmen e Aurora Miranda consecutivamente. Do mesmo modo, as mídias passam comentar que esse estilo representa a canção popular nacional e, com o alcance do cinema e do rádio juntos, a população poderia ser educada nacionalmente a respeito de seus símbolos (VIERA, 1987, p.142; GARCIA, 2004, p.70-71). A "cultura nacional" vinha sendo delimitada, homogeneizada e irradiada à partir do centro do poder político, o Rio de Janeiro, Capital Federal. Em 1937 Cetúlio Vargas cria o Instituto Nacional do Cinema- INCE, que tinha o intuito direto de incorporar artistas e intelectuais em torno da política cultural do Estado Novo e lançar diretrizes que norteariam as produções brasileiras em direção ao patriotismo, porém, a alegorização carnavalesca do Brasil não era 0 que pretendia o INCE (SIMIS, 1996, p.34; LIN0, 2007, p.167). 


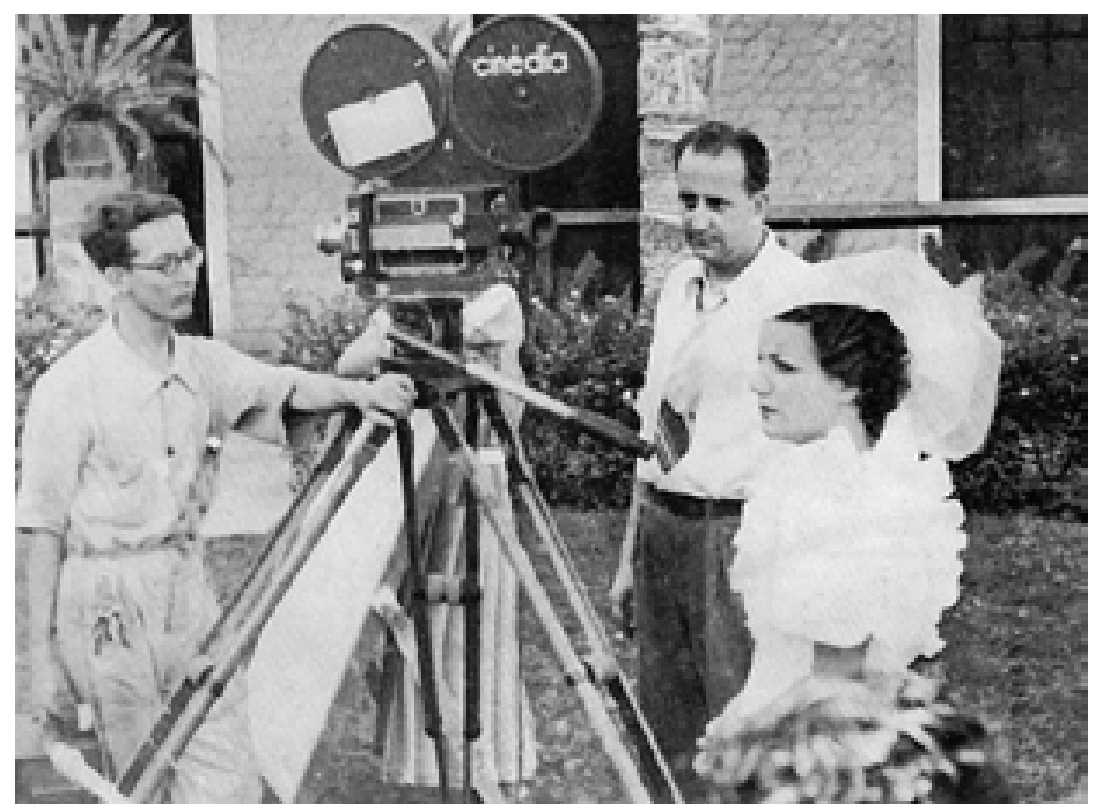

Figura 2 - Carmen Miranda nas gravações de Alô, Alô Brasil

Com os primeiros sucessos obtidos, os cineastas não hesitariam mais em usar o carnaval e o samba como panos de fundo, daí em diante vieram à tona uma série de artistas e ritmos populares. Inclusive as festas juninas viraram tema (0s Estudantes, 1935), o importante era criar pretextos para os números musicais, fórmula que funcionou muito bem até os anos 1950 (AUGUSTO, 1989, p.91). Nessa ocasião, os estúdios cinematográficos brasileiros finalmente entraram em um ritmo industrial de produção, inspirando-se nos filmes estadunidenses, deram uma abordagem mais popular ou mais "nacional" aos seus filmes. Seus produtores queriam justamente atingir a massa, promovendo diversão barata e de pouca reflexão. Tacitamente, os filmes emitiam a mensagem de que éramos pouco civilizados e que éramos naturalmente rudes, a ideia era reforçada pelos tipos "grotescos"3 que assinalavam as chanchadas (GOMES, 1996, p.74). 0 filme "Bonequinha de Seda" (1936) deixa isso claro, quando entende que uma moça fina e bem educada só poderia mesmo vir de Paris, ou seja, jamais poderia ser brasileira (VIERA, 1987, p.147).

0 ciclo do carnaval foi o grande filão, os filmes saíam pouco antes do evento e alimentavam sua própria importância. Protagonizavam as películas os maiores nomes dos discos e do rádio, deste modo, a partir do carnaval, a rádio, o cinema e os artistas ganhavam novo fôlego perante o público, jamais uma festa havia ganho tamanha proporção na mídia (MENDONÇA, 1999, p.33-35). Cinema, Rádio e Indústria

3 Ver SODRÉ, Muniz. A comunicação do grotesco: introdução à cultura de massa brasileira . 9. ed. Petrópolis: Vozes, 1983; SAMPAIO, Silveira. Trilogia do herói grotesco: teatro. Rio de Janeiro: Civilização Brasileira, 1961; ESQUIVEL, Talita Gabriela Robles. Corpo grotesco. Dissertação (mestrado) - Universidade do Estado de Santa Catarina, Centro de Artes, Programa de Pós-Graduação em Artes Visuais, Florianópolis, 2009; ECO, Umberto. História da feiúra. Rio de Janeiro: Record, 2007. 


\section{Cinema Brasileiro, Hollywood e a Política da Boa Vizinhança da Década de 1930: Um Panorama Para Carmen Miranda}

Fonográfica formavam uma tríade interdependente que girava o capital no país, ao mesmo tempo em que promovia a integração nacional através da canção popular. As músicas de carnaval eram "lançadas de preferência no final do ano, viajando através do disco e do cinema pelo território nacional em tempo de serem aprendidas e cantadas nos dias de folia" (GARCIA, 2004, p.41). Mas a transição do rádio para o cinema não fácil para muitos artistas, pois diante das câmeras precisavam se preocupar com a imagem, com os movimentos, com a interpretação e especialmente em contagiar o público com sua performance. Isso foi uma grande oportunidade para Carmen, que passou a dar ainda mais ênfase a seu figurino e sua performance, buscando sempre valorizar seu corpo e seus movimentos no palco, fazia de si um chamariz. Fruto disso foram os sete filmes que participou na década de $1930{ }^{4}$ (GARCIA, 2004, p.68). Carmen passou às telas e logo ganhou ares de estrela hollywoodiana, era aquela que tem "it na voz e no gesto", figura obrigatória nos filmes carnavalescos (MENDONÇA, 1999, p.33-35).

Por conseguinte, o carnaval começa a ser disseminado como um estilo de "ser" carioca e um estilo de "ser" brasileiro. Há certo tempo, a boemia e o samba vinham sendo borrifados pelo Brasil através dos discos, mas com a ascensão do cinema falado e cantado, a história ganha nova forma e som, estabelecendo o início da difusão de um modelo pela sedução de imagens selecionadas. A essa altura, a capital era a vitrine do país e o culto ao lazer estabelecia a nova identidade cultural do Rio. Belezas naturais, praia, samba, carnaval, todos frequentados pelas boas famílias, a herança negra e a pobreza deveriam ser despachados para as margens da cidade (MENDONÇA, 1999, p.39).

\section{0 nacionalismo em produção}

a turma do cinema daquela época estava na expectativa que o governo abraçasse esta causa como nacionalista e Ihes dessem mais incentivos. Entretanto, o tipo de cinema aprovado pelo Estado era aquele que ele mesmo produzia e podia controlar. Na linha literalmente propagandista, eram realizados documentários de exibição obrigatória, que mostravam as realizações do governo e os atos das autoridades. Ainda que fossem usadas imagens reais, eram utilizadas apenas as cenas que favorecessem a visão do governo e, sistematicamente difundissem a visão que o Estado Novo queria de si mesmo. Não eram mostras imagens de multidões nem de pessoas aplaudindo, porém se ouvia o som das mesmas, fazendo dos espectadores daquelas cenas, testemunhas de um fato que nunca ocorreu

4 “0 Carnaval Cantado no Rio" (1932- Documentário de média-metragem com cenas reais do Carnaval no Rio, primeira aparição de Carmen Miranda no cinema como artista famosa); “A Voz do Carnaval" (1933); "Estudantes" (1935); "Alô, Alô, Brasil” (1935); “Alô, Alô, Carnaval” (1936); "Banana da Terra" (1939); “Laranja da China" (1939). 
(BERNARDET, 1994, p.39-40). Antes da exibição de qualquer filme nos cinemas do Brasil, era obrigatório passar o Cinejornal Brasileiro, produzido pela DIP e que mostrava eventos esportivos e culturais, mensagens patrióticas e o presidente (LINO, 2007, p.167; MENDONÇA, 1999, p.47).Vargas entendeu o potencial do cinema e assim o descrevia:

...entre os mais úteis fatores de instrução, de que dispõe o Estado moderno, inscreve-se o cinema. Elemento de cultura, influindo diretamente sobre o raciocínio e a imaginação, ele apura as qualidades de observação, aumenta os cabedais científicos e divulga o conhecimento... Associando ao cinema o rádio e o culto racional dos desportos, completará o Governo um sistema articulado de educação mental, moral e higiênica, dotando o Brasil dos instrumentos imprescindiveis à preparação de uma raça empreendedora, resistente e varonil. E a raça que assim se formar será digna do patrimônio invejável que recebeu (VARGAS, apud LINO, 2007, p. 165-166).

A produção destes documentários era vasta, chegando ao ponto de os cineastas brasileiros protestarem, pois os exibidores preferiam projetar em suas telas 0 material obrigatório do governo ao invés do resto da produção nacional (CARCIA, 2005, p.149).

Tanto nos documentários como nos filmes históricos e nos chamados filmes educativos que o governo encomendava, se priorizava uma estética naturalista, criando nos espectadores a ilusão de estarem diante dos fatos narrados. Nessas produções existia um ocultamento da linguagem, a história "é mostrada como se fosse a única interpretação do fato" (BERNARDET, 1994, p.15). Para o Estado, o foco do cinema deveria ser o mesmo difundido pelos outros meios, reeducar a massa brasileira conforme essa nova leitura e difundir positivamente o Brasil. Mas as produções nacionais com frequência iam na contramão das expectativas do Estado, e mostravam o que a mídia considerava uma tradição de bárbaros e selvagens, jocosos, caricaturais (LIN0, 2007, p.168), apresentando traços mestiços como característicos da identidade nacional, dando ao Brasil uma imagem de especificidade frente aos estrangeiros nada desejada, narrando um brasileiro que nenhum brasileiro gostariam de ser (Renato Ortiz, 1993: 25, apud RIVERA, 2000, p. 70).

No entanto, as grandes massas pareciam adorar aquilo tudo e isso foi o suficiente para convencer Hollywood do carisma da estrela Carmen Miranda e da fórmula adotada. Enquanto o governo brasileiro propunha seu ponto de vista através de documentários literais e enfadonhos, desbancando em certo nível as demais produções nacionais, o governo estadunidense trazia sua ideologia sorrateiramente, apoiando as grandes produções Hollywoodianas em histórias românticas que contagiavam o mundo. Apesar dos Estados Unidos também praticarem os cinejornais e o cinema literalmente propagandista, nesse ponto, o cinema praticado em Hollywood e voltado para o mercado era mais eficaz na transmissão mundial de sua ideologia, do que o próprio cinema nazista, marcado pela grandiosidade opressora 
delineada pela cineasta Leni Riefenstahl. Inspirados pelos filmes desta última, o major e diretor Frank Capra, produziu uma série de documentários e filmes que ilustravam as origens da guerra e a americanização, provando que os filmes românticos, como "A Felicidade não se compra" ("It's a Wonderful Life"), foram mais eficazes na "americanização", especialmente dentre os próprios estadunidenses, que também precisavam ser comovidos pelo espírito da guerra (TOTA, 2005, p.25; FRIEDRICH, 1989, p.159).

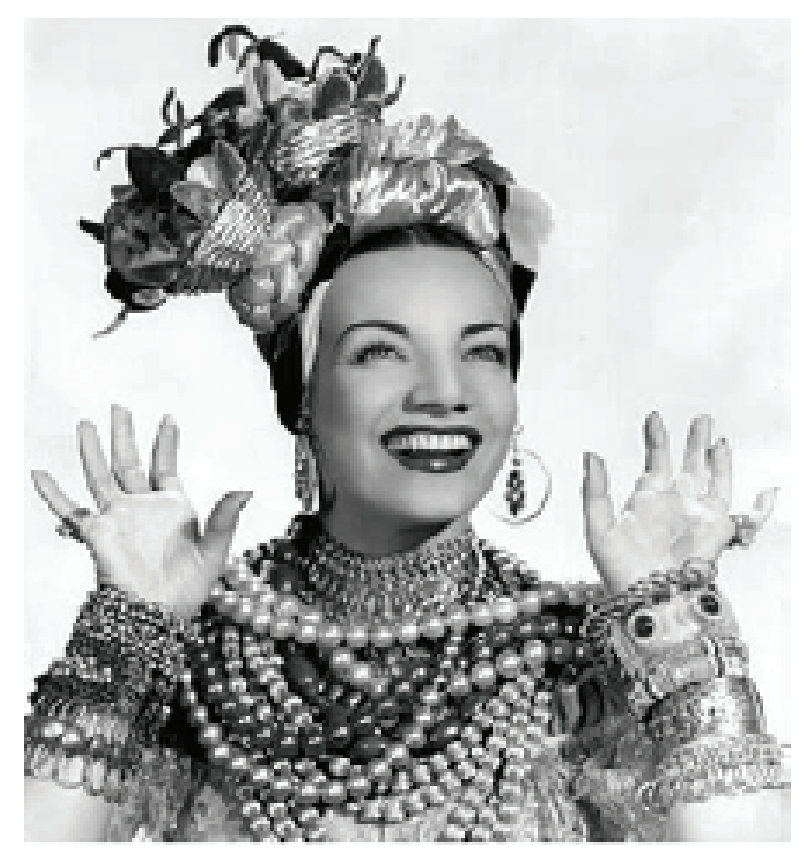

Figura 3 - Carmen Miranda vestindo a baiana pela primeira vez no filme Banana da Terra

Ao final dos anos 1940, no Brasil a chanchada impunha-se como proposta de cinema, condensando nas telas o estilo do rádio e da revista (GOMES, 1996, p.73). A chanchada e a revista estavam sintonizadas e viviam em constante troca, combinando um "humor circense, rústico e popular, com o espetáculo do cabaré". Os artistas da revista atuavam nas chanchadas e "o rádio servia como pano de fundo para essa produção cultural massiva" (LENHARO, 1995, P.55). 0 ponto alto dessas produções, é que elas conseguiam transmitir de forma leve e cômica muitos dos problemas sociais e dos assuntos políticos, porém, a revista tinha uma vantagem temporal sobre a chanchada, pois renovavam-se muito rapidamente, tinham contato direto com o público e as apresentações aconteciam no calor do momento, denunciando demagogia política, desleixo administrativo, corrupção, carestia, problemas no transporte, falta de água, entre outras coisas, na hora em que aconteciam. Contudo, os filmes dessa linha geralmente eram caracterizados por enredos ruins e sem sentido, privilegiando os números musicais. A decadência desse gêneros chegou ao final nos anos 1950, junto com chegada da televisão (VENEZIANO, 1991; ANTUNES, 2002, p.11; LENHARO, 1995, P.54). 
Dentro desse gênero, em 1939 foi lançado "Banana da Terra", do qual saiu a canção que viraria tema de Carmen Miranda, "0 que é que a baiana tem" e a faria vestir a personagem pela primeira vez. Concomitantemente às exibições do filme, o número de Carmen foi adaptado para uma apresentação no Cassino da Urca, nesse momento, Carmen interpretando a novíssima baiana chamou a atenção do empresário estadunidense Lee Schubert, que a convidou para a Broadway (VIEIRA, 1987, p.151).

Dentro desse universo, em que o cinema nacional está mais forte e vem sendo marcado por características próprias, se estabelece uma fronteira entre o nacional e o estrangeiro, que serve como ponto de partida para a valorização de uma imagem emblemática de Brasil. Em um contexto permeado pela "Política da Boa Vizinhança", o discurso imagético promovido pelo cinema destaca em nível internacional a performance diferenciada de Carmen Miranda, que é saboreada pelo olhar sedento estadunidense como um prato cheio, capaz de representar toda a América Latina. Além de angariar aliados em tempos de guerra, com a adoção de artistas latinos os Estado Unidos esperavam abrir um largo mercado financeiro, e Carmen Miranda suavizou a intervenção, estruturou apolítica internacional simplesmente por estar presente naquele cenário. Assim, entendendo que o cinema foi o veículo que melhor privilegiou Carmen nesse país e que ele foi o principal divulgador e instituidor de sua imagem mítica como a "baiana", é necessário considerar como se portava o cinema naquele período, quem o assistia, a que se direcionava e com quem competia (DIDI-HUBERMAN, 2004, p. 59).

\section{Hollywood: a indústria do cinema}

no ano em que Carmen Miranda chegou nos Estados Unidos, o cinema era a décima primeira indústria em patrimônio do país, criava-se cerca de quatrocentos novos filmes por ano, os quais atraíam mais de 50 milhões de estadunidenses todas as semanas às salas de cinema, e isso representava que a população gastava dois terços do dinheiro investido em entretenimento nos cinemas. Perante uma realidade em que existiam mais cinemas (15.115) que bancos (14.952), faturavam em torno de 700 milhões de dólares anualmente e pagavam aos maiores astros mais de 400 mil dólares por ano (MALTBY, 2003, p. 114; FRIEDRICH, 1989, p.11). Hollywood então proclamava, 1939 é "o melhor ano do cinema" (BALIO, 1993, p.01).

Perante a crise, diversos estúdios faliram e tiveram que ser reorganizados, mas "a indústria como um todo floresceu", talvez porque fosse um entretenimento novo, acessivel e servisse como uma válvula de escape para os problemas, além disso, ele também não exigia matérias primas raras, como carvão e aço (FRIEDRICH, 1989, p.27 A respeito da indústria de entretenimento no período da Depressão, o presidente Roosevelt ao se referir a atuação de Shirley Temple, faz o seguinte comentário: 
Quando o estado de espírito do povo está mais baixo do que em qualquer outra época, como durante a Depressão, é esplêndido que por apenas quinze centavos um americano possa ir ao cinema e ver o rosto sorridente de uma criança [...].(FRIEDRICH, 1989, p.27).

Diferente do processo que acontecia no Brasil, a indústria cinematográfica estadunidense foi resultado da integração do processo de produção em massa com a distribuição em massa, a principal tática de sobrevivência e sucesso, foi a empregada pelos maiores estúdios de Hollywood da época (Metro-Goldwyn-Mayer -MGM, Radio-Keith-Orpheum-RKO, Warner Bros, Paramount, 2oth Century Fox), que criaram suas próprias cadeias de cinema, minando as salas independentes e estúdios menores, garantindo a distribuição e exibição de seus filmes, logo, um lucro considerável. Isso fazia parte do chamado de sistema de estúdios, um modelo horizontal que assegurava o sucesso em que os chefões do estúdio compravam propriedades, escolhiam estrelas ${ }^{5}$ c contratavam escritores e diretores, normalmente eram usados vários escritores para cada projeto e os diretores não podiam opinar muito na pré e pós-produção, pois eram os chefes do estúdio que as orientavam (MALTBY, 2003, 130-137).

Apesar do primeiro impasse gerado pelos talkies (os filmes falados), a indústria logo se recuperou com os musicais, pois eles davam um alívio aos longos diálogos com os quais o público ainda não havia se acostumado (BALIO, 1993, p.211). Assim, o gênero mesclava canções às características principais do cinema hollywoodiano, o romance imaginado, sexo imaginado, dentre outras irrealidades. São dessa época "... E o vento levou" (Gone with the Wind, 1939), “0 Mágico de 0z" (TheWizard of Oz, 1939), "Morro dos Ventos Uivantes" (Wuthering Heights, 1939) e também "0 Grande Ditador" (The Great Dictator, 1940) de Charles Chaplin, anunciando que a guerra se aproximava. Com a ascensão de Hitler vários bons cineastas, artistas, compositores, professores, físicos e outros profissionais se refugiaram do horror nazista nos Estados Unidos, enriquecendo suas produções e dando nova visão a elas (FRIEDRICH, 1989, p.26, 40, 54).

\section{Os bons-vizinhos e a penetração em terras latinas}

a facilidade de alcance das massas pelo cinema foi notada pelo governo estadunidense, que começou a se organizar para utilizá-lo a seu favor durante o contexto político que se estabelecia. 0 presidente Roosevelt toma então interesse pessoal pela Política da Boa Vizinhança, e inicia através dela um imperialismo cultural. Por conseguinte, o cinema passou a ser instrumentalizado como bem simbólico;

5 São estrelas desse período Bette Davis, Tyrone Power, Henry Fonda, Cary Grant, Carole Lombard, James Stewart, John Wayne, Merle Oberon, Laurence Olivier, Judy Garland, Jean Arthur, Greta Garbo, Marlene Dietrich, Clark Gable e Vivien Leigh (BALI0, 1993, p.01). 


\section{Cinema Brasileiro, Hollywood e a Política da Boa Vizinhança da Década de 1930: Um Panorama Para Carmen Miranda}

veículo comunicacional e arma de propaganda, destinada a agregar parceiros na empreitada bélica, articulado, pela divisão mais importante do office of the Coordinator of Inter-American Affairs- OCIAA (Escritório do Coordenador de Assuntos Interamericanos), a de Cinema. Dentre suas funções, a divisão de cinema deveria promover a produção estadunidense de filmes, distribuindo-os por todo o hemisfério ocidental, combater o cinema produzido pelo Eixo e convencer as grandes produtoras de manterem uma boa imagem do país (TOTA, 2005, p.65).

As ideologias estabelecidas durante o contexto da Segunda Guerra, e as implicações logísticas causadas por esta, fecharam boa parte do mercado europeu para os Estados-Unidos, provocando a perda de um terço do que representava a arrecadação total de Hollywood (FRIEDRICH, 1989, p.151), portanto, a luta contra 0 Eixo, mostrava-se também uma excelente oportunidade para se fazer dinheiro. Com a política de inclusão de artistas latino-americanos 6 em Hollywood, articulada pela Divisão de Cinema, muitos países da América Latina passaram a comprar os filmes em que seus conterrâneos agora apareciam. Ana Rita Mendonça ressalta que Carmen Miranda fez parte de uma política que buscava tipos "exóticos" pela América Latina para promovê-los dentro da "Política da Boa Vizinhanç̧a", eram apresentados principalmente no cinema e na Broadway (MENDONÇA, 1999, p.10). Ademais, com a guerra e os bloqueios, os filmes alemães não alcançavam mais a América Latina, deixando caminho livre para o cinema estadunidense, o qual sem concorrência e acrescentado dos novos "tipos culturais", se impôs absoluto. Tanto, que o primeiro filme de Carmen Miranda nos Estados Unidos, tirou a Fox do vermelho. Deste modo, a "americanização", anteriormente comentada, foi mais que a conquista de aliados para a guerra, foi também uma tática de penetração de novos territórios e novos mercados, que se abriram para a circulação e edificação das imagens de um império, fortalecido pela contínua reprodução destas (TOTA, 2005, p.62, 65-66).

Nesse contexto, a atuação dos Estados Unidos em relação a América Latina foi de supremacia, tratando seus vizinhos como subdesenvolvido e incapazes de gerir os seus negócios. Esta visão fica evidente em John Quincy Adams, quem primeiro estabeleceu relações diplomáticas com a América Latina e comentava que os hispânicos eram "preguiçosos, sujos, nojentos [...] uma parcela de porcos", de forma que os Estados Unidos combinavam o auto-interesse com uma "missão civilizadora", "um esforço abnegado de um povo superior, para ajudar uma civilização inferior superar seus defeitos". Nesse ínterim, o americanismo e a Boa Vizinhança eram justificados como uma forma de espantar as doutrinas que colocavam em perigo

6 Por volta de 1930 a Fox levou alguns artistas brasileiros para trabalhar em Hollywood, mas isso foi apenas uma jogada de marketing para ganhar publicidade gratuita em nossas terras. Os artistas ficavam encostados e quando surgia algum papel era de figurante. A situação foi tão grave que muitos chegaram a passar fome. (CASTR0, 2005, p.66-68) Alguns nomes latino-americanos de destaque no cinema estadunidense foram: Xavier Cugat, José Iturbi, Dolores del Rio, Lupe Vélez, e a meio-espanhola Margarita Carmen Dolores Cansino, mais conhecida como Rita Hayworth. 
os ideais democráticos comuns interamericanos (SCHOULTZ, 1998, p.05, 478, 310), mas de fato manifestavam uma lógica de sua perfeição que justificava a exploração e intervenção sobre outras culturas, a fim de homogeneizá-las como mais um produto a ser consumido, dentre estes, nossa Carmen (MAUD, 2005, p.46).

A mensagem, entretanto, deveria agregar simpatizantes e não o contrário. 0 primeiro filme de Carmen Miranda nos Estados Unidos, "Down Argentine Way" ("Serenata Tropical"-1940), causou atritos diplomáticos devido aos vários equívocos cometidos, por exemplo, Carmen canta uma rumba em português e outra atriz usa castanholas, mas nenhum dos dois existem na Argentina, local onde o filme é ambientado. Na Argentina o filme foi proibido e no Brasil muito mal falado. Mas a importância do Brasil era grande nesse contexto devido às suas proporções na América do Sul e

[...] os articuladores da política externa norte-americana tinham certeza da expansão do nazismo no Brasil, a ponto de num relatório a Rockefeller, W. Guest, funcionário oficial da política externa norte-americana para o Brasil, afirmar: 'Eu considero que o Brasil é a mais importante e a mais perigosa de todas as Repúblicas do Sul, e estou convencido de que os alemães também pensam isso. Todos os homens de seu governo são abertamente pró-nazi, com exceção do presidente Vargas e de Oswaldo Aranha' (MOTA, apud MAUD, 2005, p.48).

Para evitar mais equívocos e possíveis aliados nazistas, o OCIAA envia expedições de reconhecimento ao sul, numa delas, Walt Disney visita o Brasil e cria o personagem Zé Carioca e o filme "Saludos Amigos" (Alô, Amigos, 1943). Em seguida, Nelson Rockefeller que ocupava o cargo de Coordenador de Assuntos Interamericanos, envia também Orson Welles, conceituado pela película "Citizen Kane" (Cidadão Kane- 1941), para criar uma obra que retratasse a cultura brasileira e o carnaval do Rio, mas a empreitada não surtiu bons resultados, as cenas de Orson mostravam pessoas comuns, gente do povo e vários negros se divertindo pelas ruas. Hollywood obviamente desprezou suas filmagens, pois nada traziam da estética comercial e alegórica que vendiam dessas bandas (D'ARAUJ0, 2000, p.39). Além dos interesses cinematográficos, as expedições eram feitas para verificar quais eram as tendências nacionalistas e nazistas dos países daqui. Daí em diante, combinando os interesses imperialistas a uma melhor reprodução da cultura latina, como acreditavam, levou Hollywood a dar enfoque aos filmes com temas latino-americano (TOTA, 2005, p.64-65; FRIEDRICH, 1989, p.151).

A partir daí cria-se uma padronização de representação, em que as identidades nacionais são construídas a partir de diferenças gritantes, porém, culturalmente aceitáveis. Que ilustram o selvagem que precisa ser civilizado pela cultura superior.

Os protocolos de visualidade definidos pelo CIAA deveriam ser compartilhados pelo conjunto de seus representantes, nas suas viagens pelas 'demais Repúblicas Americanas'. Logo depois de retornar de seu tour da Boa Vizinhança, Walt Disney produziu Alô Amigos (1943), um simpático 
desenho animado, no qual se relatou em cores variadas e tons fortes 0 passeio dos desenhistas na busca da imagem ideal da América Latina. Para cada país buscou-se um equivalente, um semelhante, para dar sentido a essa comunidade imaginada que se buscava forjar entre as Américas. Em cada país, também a alteridade era definida pela estética do pitoresco. As imagens de Disney perseguem o padrão da dicotomia que diferencia 'nós' dos 'outros' (MAUD, 2005, p.68).(grifos meus)

Porém, a tentativa de não mais ridicularizar os personagens latino-americanos jamais foi atingida pelo OCIAA, e nas palavras de Vinícius de Moraes, se fez a crítica à fórmula adotada pelos Estados Unidos que muitos brasileiros gostariam:

Há uma incapacidade fundamental em Hollywood para arrancar qualquer coisa de boa de um caráter hispano-americano. Lançam-se mãos de cactos, haciendas coloniais, lovely señoritas, masterful hidalgos, guapos caballeros, que ao se despedirem gritam-se com originalidade de dar calafrios na espinha: 'Adios amigo!'. Dança-se o tempo todo, fandangos, rumbas, congas, sambas. Há sempre uma serenata de guitarra onde um nostálgico muchacho canta uma 'Paloma' qualquer sob um fatídico balcony enluarado. Tivesse o Cinema a desgraça de ser, além de falado, sensivel ao olfato, e haveria cheiros de jasmim e de estrume fresco embriagando o ambiente (MORAES, 1991, p.81).

Por mais ácida e verdadeira que fossem as colocações de Vinícius, ainda que a propaganda feita não nos representasse a contento a latinidade e a brasilidade, este foi um primeiro passo para a difusão internacional do Brasil com portador de características próprias, e por mais que houvesse a caricatura, nesse momento também aconteceu uma abertura internacional para uma série de outros artistas e intelectuais brasileiros e uma valorização de nossas culturas. em 1940 Candido Portinari expõe seu trabalho no MoMA, Érico Veríssimo é convidado a ministrar um curso de literatura brasileira na Universidade de Berkeley-Califórnia e Carmen Miranda brilhava Broadway. Nesse período vieram para cá Pierre Verger, Genevieve Naylor, Gotherot e Lévi-Strauss (SILVA, 2008, p.05; MAUD, 2005, p.61), dando um olhar etnográfico nunca feito antes. Em Hollywood, muito embora o que a "Embaixatriz do samba" cantasse não fosse exatamente o samba brasileiro- mas uma mistura de habanera, rumba, samba-jongo, tango, marchinha e outros gêneros que cabiam melhor no gosto dos estadunidenses-, ocorrendo uma forte disseminação de pandeiros e uma vasta interação da música que se fazia aqui com a de lá (TOTA, 2005, p.118; SOUZA, 2004, p.77). Entre 1939 e 1945 (período dos filmes de sucesso da 2oth (entury-Fox), Carmen realmente estava representando uma cultura brasileira nos Estados Unidos, porém, em uma representação travestida, através de uma homogeneização ou diluição cultural construída por uma série de fatores e de interesses políticos e econômicos (como comentamos anteriormente). Uma vez que a cultura é um ente dinâmico e sofre influências exógenas 
0 Cinema Brasileiro, Hollywood e a Política da Boa Vizinhança da Década de 1930: Um Panorama Para Carmen Miranda

constantemente, nem a própria versão de samba que os brasileiros consideravam como música "tipicamente brasileira" era isenta das transformações sociais e requintes estrangeiros. Finalmente, como fruto dessas relações, o samba, a carnavalidade, a feminilidade e a alegria se tornaram moedas de troca, que vem cunhando por quase um século a expressão do brasileiro. 


\section{REFERÊNCIAS BIBLIOGRÁFICAS}

> ANTUNES, Delson. Fora do sério: um panorama do Teatro de Revista no Brasil. Rio de Janeiro: FUNARTE, 2002.

> AUGUSTO, Sergio. Este mundo é um pandeiro: a chanchada de Getúlio a JK. São Paulo: Companhia das Letras, 1989.

> BALIO, Tino. History of the American cinema. Vol.5. Grand design : Hollywood as a modern business enterprise- 1930 -1939. Estados Unidos, New York: Simon $A$ Schuster Macmillan, 1993.

> BERNARDET, Jean Claude. Historiografia clássica do cinema brasileiro: metodologia e pedagogia. 3 ed. São Paulo: AnnaBlume, 2004.

> BERNARDET, Jean-Claude; RAMOS, Alcides Freire. Cinema e história do Brasil. 3. ed. São Paulo: Contexto, 1994.

> CASTRO, Ruy. Carmen: uma biografia. São Paulo: Companhia das Letras, 2005.

> DIDI-HUBERMAN, Georges. Imágenes pese a todo: memoria visual del holocausto. Barcelona: Paidós Ibérica, 2004.

$>$ FRIEDRICH, Otto. A cidade das redes. Hollywood nos anos 40. São Paulo: Cia das Letras, 1988.

$>$ GARCIA, Nelson Jahar. Estado Novo. Ideologia e propaganda política. São Paulo: Loyola, 2005.

> GARCIA, Tânia da Costa. 0 "it verde e amarelo de Carmen Miranda. São Paulo: AnnaBlume; Fapesp, 2004.

> GOMES, Paulo Emílio Sales. Cinema: trajetória no subdesenvolvimento. 2. ed. Rio de Janeiro: Paz e Terra, 1996.

> LENHARO, Alcir. Cantores do rádio: a trajetória de Nora Ney e Jorge Goulart e o meio artístico de seu tempo. Campinas: Unicamp, 1995.

> LINO, Sônia Cristina. Projetando um Brasil moderno. Cultura e cinema na década de 1930. Locus: Revista de História, Juiz de Fora, v. 13, n. 2, p. 161-178, 2007. Disponível em: < http://www.ufjf.br/locus/files/2010/02/95.pdf >. Acesso em:03 de abril de 2011.

> MALTBY, Richard. Hollywood cinema.UK, Oxford: Blackwell Publishing, 2003.2

> MAUAD, Ana Maria. Genevieve Naylor, fotógrafa: impressões de viagem (Brasil, 1941-1942). In Revista Brasileira de História. São Paulo, v. 25, nć 49, junho de 2005.

$>$ MENDONÇA, Ana Rita. Carmen Miranda foi a Washington. Rio de Janeiro: Record, 1999.

> MORAES, Vinicius de; CALIL, Carlos Augusto. 0 cinema de meus olhos. São Paulo: Companhia das Letras, 1991.

> RIVERA, Mareia Quintero. A cor e o som da nação, a idéia de mestiçagem na crítica musical do caribe hispânico e do Brasil (1928-1948). São Paulo: Annablume Editora, 2000. 
> SCHOULTZ, Lars. Beneath the United States: a history of U.S. policy toward Latin America. Estados Unidos, Cambrigde: Harvard University Press, 1998.

> SILVA, Guilherme A. do N. e; LIMA, Jonatas P. A Política de Boa Vizinhança e a influência cultural estadunidense na América Latina. In Contemporâneos- Revista de Artes e Humanidades. Viçosa, n. 2, Maio/Outubro 2008. ISSN 1982-3231. Disponível em: 〈http://www.revistacontemporaneos.com.br/n2/pdf/politicadeboavizinhanca.pdf >. Acesso: 11 de abril de 2011.

> SIMIS, Anita. Estado e cinema no Brasil. São Paulo: AnnaBlume, 1996.

> SOUZA, Eneida Maria de. Carmen Miranda: do kitsch ao cult. In: CAVALCANTE, Berenice.; STARLING, Heloisa Maria Murgel; EISENBERG, José. Decantando a república v.2: inventário histórico e político da canção popular moderna brasileira. Retrato em branco e preto da nação brasileira. Rio de Janeiro: Nova Fronteira; São Paulo: Fundação Perseu Abramo, 2004. P.73-87.

> TOTA, Antônio Pedro. 0 Imperialismo sedutor: a americanização do Brasil na época da Segunda Guerra. São Paulo: Companhia das Letras, 2000.

$>$ VENEZIANO, Neyde. 0 teatro de revista no Brasil: dramaturgia e convenções . Campinas: Ed. da UNICAMP, 1991.

> VIEIRA, João Luiz Vieira. A chanchada e o cinema carioca (1930-1955). Módulo 4. In: RAMOS, Fernão (organizador). História do cinema brasileiro. São Paulo: Art Editora, 1987. p.131-187.

*0 presente artigo faz parte do Trabalho de Conclusão de Curso da autora, "Perfis de Carmen Miranda: diferentes contextos de uma imagem apropriada (1939-2011)".

Káritha Bernardo de Macedo, bacharel em Moda - Universidade do Estado de Santa Catarina- UDESC

karitha23@yahoo.com.br 